\title{
EFFECT OF WORKPLACE STATUS ON GREEN CREATIVITY: AN EMPIRICAL STUDY
}

\author{
YANG, Z. ${ }^{*}$ YE, L. - GUO, M. \\ School of Economics and Management, Beijing JiaoTong University, Beijing 10044, China \\ *Corresponding author \\ e-mail:16113169@bjtu.edu.cn
}

(Received $8^{\text {th }}$ Mar 2019; accepted $1^{\text {st }}$ May 2019)

\begin{abstract}
In organizations, green creativity of the employees is an essential part of implementing sustainable development. Our research proposed that workplace status has a significant impact on green creativity. Through an empirical study, we came to the conclusion that an increase in workplace status can lead to green creativity and prosocial motivation mediates the process. Since workplace status promotes the attention for group interests, employees will evaluate their self-worth considering the sustainable development of the environment. Based on the analysis framework of moderated mediation model, this study indicated that organization identification had a positive moderating effect on the relationship between workplace status and green creativity, and it is the boundary condition for workplace status to be effective.

Keywords: prosocial motivation, organization identification, moderated mediation model, sustainable development, innovation
\end{abstract}

\section{Introduction}

With the aggravation of environmental problems, researchers in different areas have been studying the issues of global ecosystem protection and sustainable development of the human environment. Responding to environmental challenges, a new manifestation of innovation can bring competitive advantages for organizations (Chen and Chang, 2013). As a result, green creativity has received widespread attention for it enables firms to gain competitive advantages (Gong et al., 2018). The notion of green creativity represents behaviors when companies or individuals propose new ideas for environmental sustainability (Amabile et al., 1996). Among them, natural scientists focus mainly on the technical perspective, which includes how to develop and apply pro-environmental materials and energies (Du et al., 2018; Huppmann et al., 2019), and how to design production models that cause the least harm to the environment (Pombo et al., 2019; Moratis and Melissen, 2019). However, environmental sustainability is ultimately an issue of human behavior, which depends on the complex relationships between individuals, society and natural environment. In other words, it is the interaction of people in the social system with the environment that play a significant role in sustainable development. At the micro level of psychological cognition, green creativity refers to the behavior where individuals generate new ideas to reduce ecological damage, protect natural resources and promote the sustainable development of the economy and the environment (Chen and Chang, 2013). In other words, green creativity reflects the inherent knowledge, beliefs, and value conception systems of an individual or an organization (Song and Yu, 2018; Lichtenfeld et al., 2018). Currently, green creativity has gradually become a research hotspot in social psychology and environmental psychology (Aebischer, 2003; Eisenhandler, 2009; Song and Yu, 2018). Exploring the psychosocial mechanisms of green creativity will not only identify factors 
that impede positive environmental behavior but also clarify mechanisms that promote positive environmental behavior. In addition, more and more researchers are starting to focus on the social interaction under in an organization context (Song and $\mathrm{Yu}, 2018$ ).

However, in the perspective of social psychology or environmental psychology, many scholars have discussed the ways of promoting individual green creativity from the aspects of environmental education, suggestion, reinforcement and feedback (Albort-Morant et al., 2016; Zhu et al., 2018; Zhou et al., 2018; Wang et al., 2018). In fact, personality, self-construal, intrinsic motivation and extrinsic motivation will influence social interaction and green creativity (Amabile, 1997; Hennessey and Amabile, 1998; Sawyer, 2017). In recent research, the relationship between organizational situational factors and green creativity are attracting more and more attention, this article will integrate existing research from the perspective of social psychology. Based on the multi-dimensional perspectives such as psychology, society, and culture, will be good for constructing an effective model and institutional design transformation. Therefore, this paper will systematically study the relationship between workplace status and green creativity, with the purpose of providing some reference for future research and policymaking in this field.

In management practice, workplace status as an incentive means widely exists in the design of organizational systems (Djurdjevic et al., 2017). In general, people are eager to gain respect, admiration, and voluntary obedience from other members of the organization (Magee and Galinsky, 2008), and this kind of respect or admiration from others is called workplace status. Status is a concept of sociology, which refers to the universally recognized ranking of individuals in their organization, and the level or grade of a person in an organization. For individuals, workplace status represents the quantity and quality of individuals' valuable resources in the organization (Zinko et al., 2012). Workplace status affects an individual's resources, development and determines how individuals are restricted in the workplace. As the high value and high demand for workplace status, it is very common for using status as an approach of encouragement. However, how does workplace status affect employee green creativity and the underlying mechanisms are unclear. In terms of influencing factors, little research has paid attention to the internal mediation effect of workplace status on green creativity. Therefore, in this study, we consider how workplace status can contribute to enhancing employees green creativity and explore the boundary conditions for this process.

\section{Research background and hypotheses}

Academic research on pro-environmental behavior has a history of nearly 40 years. Green creativity as a representative of pro-environmental behavior is the driving force of sustainable development, therefore every company wants to stimulate the green creativity of its employees more effectively. According to Jia et al. (2018), improving green creativity depends on cooperation between company environmental strategies and corresponding human resource management (HRM) practices. Research on green human resource management mainly focuses on the encouragement of employees to come up with new green ideas and actively participate. The green creativity of employees is of great significance to the sustainable development of enterprises. Therefore, how to effectively stimulate the green creativity of employees in management has received extensive attention. 


\section{Workplace status and green creativity}

Workplace status reflects the respect and admiration in the workplace, and it requires both recognition and good relationships. In order to gain a position in the workplace, a person needs to make great efforts to make their competence recognized. Then, the person must show a friendly attitude to get a warm impression. In general, workplace status represents the social worth of the person and everyone in the organization aim to achieve a high position in the workplace. The social worth will confer the person more useful social resource and access to acquirea positive emotion (Anderson et al., 2015).

Given the complexity of the creative process, social resources and positive emotions may motivate employees to take more participation in green innovation activities. As the high value and high demand for workplace status, it is very common for using status as an approach of encouragement. However, how does workplace status affect employee creativity and the underlying mechanisms are unclear, and little research has paid attention to the internal mediation effect of workplace status on creativity (Song and $\mathrm{Yu}, 2018$ ). As a result, it is possible to have uncontrollable outcomes in the approach of status encouragement. In other words, the idea is to use status to promote creativity may lead to the opposite result. Based on the interaction theory of creativity, this study explores the mechanism of workplace status on creativity from the perspective of the social interaction generated by green creativity (Wang et al., 2018). In the formation stage of green creativity, the higher workplace status will enhance the interactive relationship in the workplace to activate the internal resources of the organization and promote the transmission of non-redundant information contributing to an internal ecological environment conducive to green innovation (Wrzesniewski et al., 2003). Workplace status is a comprehensive reflection of the ability, prestige, resources, and influence of employees in the workplace. When someone has a high workplace status, it means that he or she will be easier to be recognized and adored. As a result, the person has more probability to believe in his ability and easier to succeed. At the same time, a higher position in the workplace can promote the continuous improvement of green innovative thinking, which is very important to the integration and realization of green ideas. Therefore, this paper assumes that individuals with higher workplace status are more likely to perform green creativity. Based on this, this paper proposed hypothesis 1 .

$H_{1}$ : Workplace status has a positive effect on green creativity.

\section{The mediator role of prosocial motivation}

Prosocial motivation refers to encouraging employees to form motivations of benefiting organizations and other members (Grant, 2007), which is a dynamic psychological factor that occurs in social interaction. Since prosocial motivation pays more attention to the interests of others, it shows altruistic behavioral tendencies and cognitive attitudes of respecting others. Workplace status has a significant impact on prosocial motivation for three reasons. First, workplace status reflects the social value of employees in the process of social interaction within the organization and forms an effective social proof in the workplace (Zhu et al., 2018). The prosocial motivation one of the most important internal motivation of individuals meets the value needs of the organization since members of the organization normally have high social expectations for those with high workplace status. Based on the expectation theory, when someone 
has a higher workplace status, he will have more internal motivation to strive for green innovation.

Second, members with high workplace status have more internal resources and have the obligation to help the organization achieve higher goals. Workplace status is the public's overall evaluation of an individual. In other words, workplace status is a characteristic or trait attributed to a person, which is an intangible capital of the subject (Anderson et al., 2015). Forming prosocial motivation is an effective way for high-level members to achieve organizational goals and this makes workplace status more socially beneficial in the organization.

Third, according to social exchange theory, when employees feel that the organization provides more support, this positive perception will promote green creativity through the mediator role of organizational commitment and job satisfaction. Employees with higher workplace status will pay more attention to the interests of others and have more prosocial behavioral tendencies. In certain circumstances, environmental information in a social situation will trigger people's green creativity intent (Lichtenfeld et al., 2018). Therefore, workplace status will stimulate the prosocial motivation, and then promoting green creativity of the employees. Based on this, we proposed hypothesis 2.

$\mathrm{H}_{2}$ : Prosocial motivation mediates the relationship between workplace status and green creativity.

\section{The moderator role of organization identification}

In terms of social perception, recent research indicates the impact of personal beliefs on green creativity. When dealing with environmental issues, people face conflicts between the two goals of achieving enjoyment and following environmental regulations. Therefore, green creativity often means a certain price. Based on the basic premise of cost-benefit, Spanjol et al. (2015) integrated factors such as values, situations, and goals in their theoretical framework. The research for green creativity follows two paths within this framework, one is the external approach, which reduces the cost of proenvironmental decision; the other is the internal approach, which is to strengthen the normative goal and digest the pro-environmental value. Compared with the external approach, the internal approach depends on the corresponding values and the situational factors that can activate such values, so the mechanism of promoting green creativity is very stable (Wang et al., 2018). Within an integrated and diversified framework of green creativity, the role of social perception still exists systematically (Huppmann et al., 2019).

Organization Identification defined as the perception and sense of belonging of individual in an organization has a dramatic impact on employee attitudes, behaviors, and perceptions (Ashforth et al., 2008). According to social identity theory, organizational members have a behavioral tendency to define their social identity according to the social situation they face. Organization identification is a comprehensive reflection of employees' social interaction in the organization and it reflects the cognitive overlap between individual and organization (Farooq et al., 2017). Through this method, an organization's interests can be internalized by employees and organizational success is equivalent to their own success. In other words, organization identification can increase an individual focus on the organization's interests members with a high level oforganization identification may achieve self-positive identity through achieving the organizational goals. This study suggests that organizational 
identity can enhance the effect of workplace status on green creativity. Therefore, this paper proposes hypothesis 3.

$\mathrm{H}_{3}$ : Organization identification moderates the relationship between workplace status and green creativity.

In summary, in order to further explore the relationship between workplace status and green creativity, this paper establishes a regulated mediation model to reveal the internal mechanism. The model is shown in Figure 1.

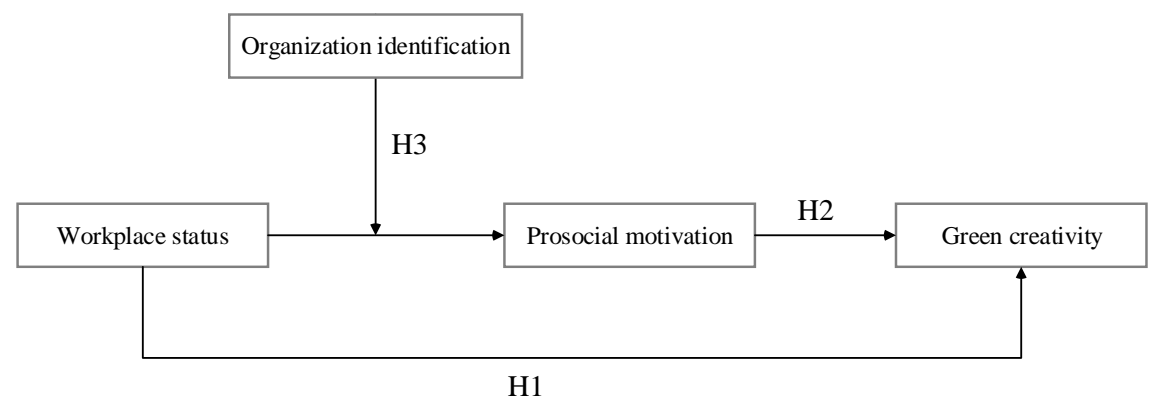

Figure 1. Theory research model

\section{Methodology}

\section{Data collection}

This research mainly aimed at front-line workers in the industry of electricity, telecommunications, and manufacturing. The survey mainly relied on relevant entrusting contact to issue questionnaires and communicated with the responsible persons in detail before the questionnaire. Forty-five companies were selected, and 400 questionnaires were distributed throughout the study. After eliminating invalid questionnaires such as repeated answers and serious missing data, 342 valid questionnaires were obtained (effectiveness 85.4\%). Among the employee samples, $54.2 \%$ were male; the education level was mainly junior college $(66.3 \%)$; the age was 26-35 years old (73.7\%); the working age was mainly 6 years $(36.4 \%)$.

The scales used in this study are mature scales widely used in at domestic and abroad areas. Accurate and reliable measurement tools are the basis for exploring green innovative influencing factors and building theoretical models. Recently, researchers havepaid more attention to the scientific and reproducible functionality of behavioral measurement models and have adopted a richer and diverse approach to integrating more effective evaluation structures.

Workplace status is measured based on the 5-question scale developed by Djurdjevic et al. (2017). The paper questionnaire is distributed on-site and the item is like "I enjoy a high status in the workplace". The prosocial motivation is based on the 4-question scale developed by Grant (2007), measuring items such as "It is important for me to have the opportunity to do my best to help others". The organization identification is based on the 6-question scale developed by Mael and Ashforth (1992), measuring items such as "The success of the organization is my success". In addition, we used the model proposed by Chen and Chang (2013) to measure green creativity, and green creativity was measured using the questionnaire in Table 1. 
All English scales were translated into Chinese using the translation-translation back program to maximize the effective understanding of the scale. The scales are all measured by Likert 7 points, from 1 to 7 , respectively, indicating that the degree of conformity to the described situation is low to high. The evaluation methods used in the study are self-subjective evaluations of the employees. Therefore, it is necessary to use a rigorous mathematical analysis method to verify the validity of the data.

Table 1. Measurement items for green creativity (Chen and Chang, 2013)

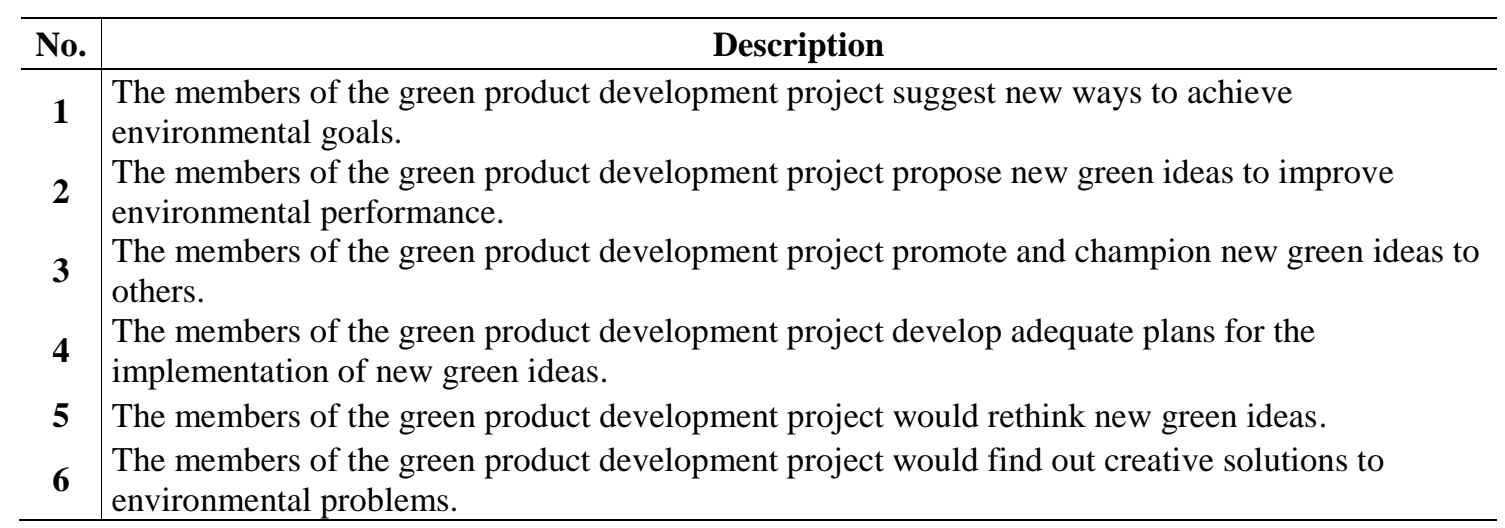

\section{The framework of moderated mediation model}

Mediation models of psychological processes are widely used in the research of organizational behavior because they can reveal the process and mechanism of the influence between variables that get more in-depth results compared with the regression analysis. Applying these models allow us to develop new ideas in theoretical development and explore the possible points of intervention in practice (Shrout and Niall, 2002). In these models, the putative intermediate variables account for the association between independent variables and outcome variables. When the empirical analysis results support the hypothesis proposed by the model, it will provide invaluable information for subsequent experimental research and theoretical exploration (Bollen and Stine, 1990; Mackinnon et al., 2002).

According to Baron and Kenny (1986), a mediation model can be written as:

$$
\begin{gathered}
M=i_{M}+a_{X}+e_{M} \\
Y=i_{Y}+c^{\prime} X+b M+e_{Y}
\end{gathered}
$$

In Equation 1 and Equation 2: $i$ represents intercept and e represents error, $M$ is the mediator between $X$ and $Y$, and the indirect effect of this model can be quantified as the product of coefficients $a$ and $b$.

In the research of management, psychology and other disciplines, the relationship between two variables is dependent on a third variable is common in many theories. The variables that affect the strength of the relationship between two variables called moderator variables. In other words, a moderation model occurs when the relationship between $X$ and $Y$ is affected by a moderator variable $Z$. According to Dawson (2014), a moderation model can be written as Equation 3. 


$$
Y=i_{1 Y}+i_{2 Y} Z+c_{1} X+c_{2} X Z+e_{Y}
$$

When a model contains both mediation variables and moderation variables, it is called a moderated mediation model. According to the basic concepts of the model, a moderated mediation effect occurs when the mediation effect changes with the moderating variable, see in Figure 2. Based on previous research (Wang and Preacher, 2015), a moderated mediation model can be written as Equation 4 and Equation 5.

$$
\begin{gathered}
M=i_{1 M}+i_{2 M} Z+a_{1} X+a_{2} X Z+e_{M} \\
Y=i_{1 Y}+i_{2 Y} Z+c_{1}{ }^{\prime} X Z+c_{2}{ }^{\prime} X Z+b_{1} M+b_{2} M Z+e_{Y}
\end{gathered}
$$

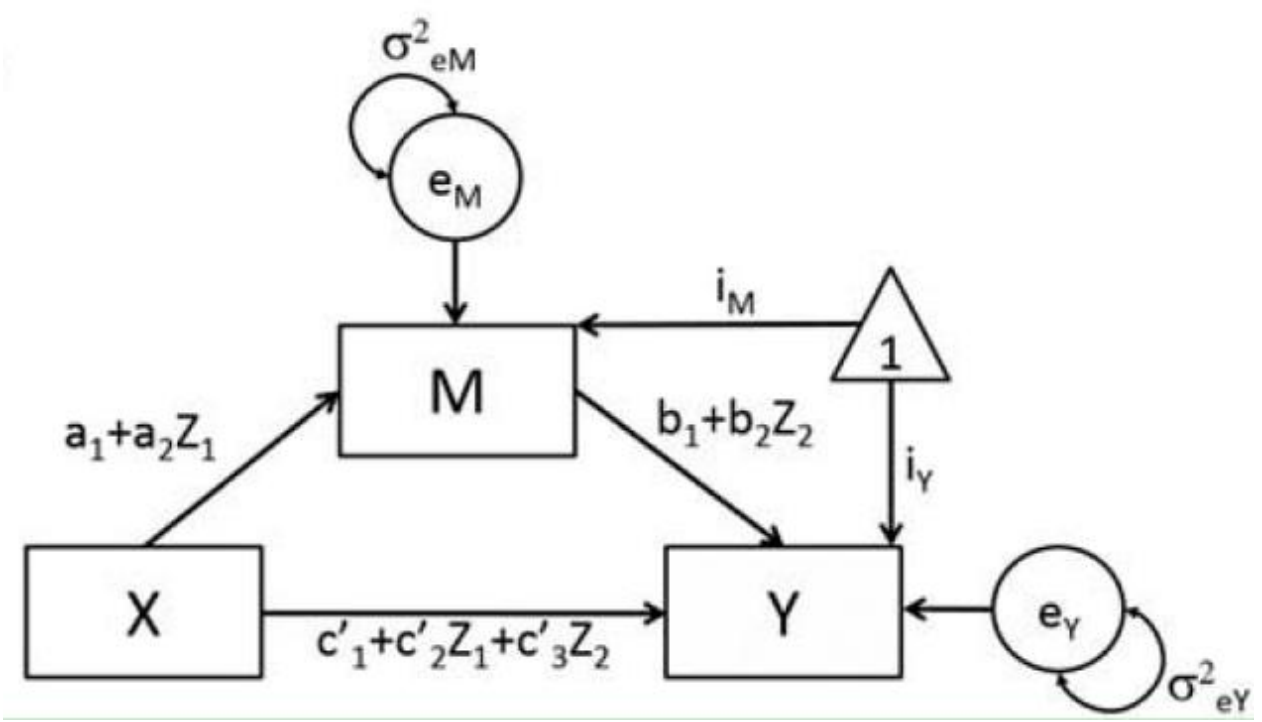

Figure 2. A moderated mediation model (Wang and Preacher, 2015)

\section{Results and analysis}

\section{Validity and reliability analysis}

The exploratory factor analysis and reliability analysis results of the scale are shown in Table 2 and Table 3. From Table 2, the interpretable variance of pro-environmentally behaviors is $21.59 \%$, the interpretable variance of organization identification is $19.50 \%$, the interpretable variance of workplace status is $17.06 \%$, and the interpretable variance of prosocial motivation is $14.53 \%$. And greater than $50 \%$. Therefore, this test has good explanatory validity.

It can be seen from Table 3 that the internal consistency coefficients of all the scales in this study exceeded 0.89 , indicating that they all have good measurements.

\section{Descriptive statistics}

Table 4 shows the correlation between the various constructs. From the data in the table, the correlation between the variables is good, and the hypothesis is initially supported. 
Table 2. Factors, loadings, eigenvalues and explained variance of each factor

\begin{tabular}{|c|c|c|c|c|}
\hline Factor & Items & Loading & Eigenvalue & Variance \\
\hline \multirow{6}{*}{ Green creativity } & GC3 & 0.861 & \multirow{6}{*}{10.601} & \multirow{6}{*}{$21.59 \%$} \\
\hline & GC2 & 0.820 & & \\
\hline & GC4 & 0.817 & & \\
\hline & GC1 & 0.817 & & \\
\hline & GC5 & 0.687 & & \\
\hline & GC6 & 0.670 & & \\
\hline \multirow{6}{*}{ Organization identification } & OI4 & 0.799 & \multirow{6}{*}{1.991} & \multirow{6}{*}{$19.50 \%$} \\
\hline & OI2 & 0.770 & & \\
\hline & OI1 & 0.752 & & \\
\hline & OI5 & 0.751 & & \\
\hline & $\mathrm{OI} 3$ & 0.680 & & \\
\hline & OI6 & 0.647 & & \\
\hline \multirow{5}{*}{ Workplace status } & WP4 & 0.806 & \multirow{5}{*}{1.530} & \multirow{5}{*}{$17.06 \%$} \\
\hline & WP3 & 0.787 & & \\
\hline & WP2 & 0.784 & & \\
\hline & WP5 & 0.704 & & \\
\hline & WP1 & 0.642 & & \\
\hline \multirow{4}{*}{ Prosocial motivation } & $\mathrm{PM} 2$ & 0.774 & \multirow{4}{*}{1.140} & \multirow{4}{*}{$14.53 \%$} \\
\hline & PM1 & 0.759 & & \\
\hline & PM3 & 0.759 & & \\
\hline & PM4 & 0.751 & & \\
\hline
\end{tabular}

Table 3. Internal consistencies, mean scores and standard deviations of the scales

\begin{tabular}{c|c|c|c}
\hline Subscale & Cronbach's alpha & mean score & standard deviation \\
\hline Green creativity & 0.923 & 6.024 & 0.921 \\
Organization identification & 0.901 & 5.251 & 1.270 \\
Workplace status & 0.891 & 4.731 & 1.189 \\
Prosocial motivation & 0.910 & 5.506 & 1.130 \\
\hline
\end{tabular}

Table 4. Inter correlations between subscales

\begin{tabular}{c|c|c|c|c}
\hline Subscale & $\mathbf{1}$ & $\mathbf{2}$ & $\mathbf{3}$ & $\mathbf{4}$ \\
\hline 1.Green creativity & 1 & $0.591^{* *}$ & $0.533^{* *}$ & $0.635^{* *}$ \\
2.Organization identification & & 1 & $0.606^{* *}$ & $0.611^{* *}$ \\
3.Workplace status & & & 1 & $0.618^{* *}$ \\
4.Prosocial motivation & & & & 1 \\
\hline
\end{tabular}

$* \mathrm{p}<0.05, * * \mathrm{p}<0.01$

\section{Discriminant validity analysis}

In order to test the discriminant validity between the main variables, this paper conducts a confirmatory factor analysis of workplace status, prosocial motivation, green creativity, and organization identification. As shown in Table 5, compared with the other four competing models, the four-factor model is optimally fitted, and each parameter can reach the fitting standard $\left(X^{2} / d f=3.66, N F I=0.96, I F I=0.97, G F I=0.94\right.$, $R M S E A=0.068, S R M R=0.054)$, indicating that the four variables in this study have good discriminant validity, see in Figure 3. 
Table 5. Confirmatory factor analysis results

\begin{tabular}{|c|c|c|c|c|c|c|c|c|}
\hline Model & $\mathbf{X}^{2}$ & df & $X^{2} / \mathrm{df}$ & RMSEA & NFI & IFI & GFI & SRMR \\
\hline $\begin{array}{l}\text { The best one-factor model } \\
(\mathrm{WP}+\mathrm{PM}+\mathrm{GC}+\mathrm{OI})\end{array}$ & 2902.00 & 189 & 15.35 & 0.205 & 0.88 & 0.89 & 0.55 & 0.099 \\
\hline $\begin{array}{l}\text { The best two-factor model A } \\
(\mathrm{WP}+\mathrm{OI}, \mathrm{PM}+\mathrm{GC})\end{array}$ & 2281.79 & 188 & 12.14 & 0.181 & 0.91 & 0.92 & 0.61 & 0.091 \\
\hline $\begin{array}{l}\text { The best two-factor model B } \\
(\mathrm{WP}, \mathrm{PM}+\mathrm{GC}+\mathrm{OI})\end{array}$ & 2377.94 & 188 & 12.64 & 0.185 & 0.90 & 0.91 & 0.60 & 0.089 \\
\hline $\begin{array}{l}\text { The best three-factor model } \\
\text { (WP, PM+GC, OI) }\end{array}$ & 1581.18 & 186 & 8.50 & 0.148 & 0.93 & 0.94 & 0.69 & 0.079 \\
\hline $\begin{array}{l}\text { The best four-factor model } \\
\text { (WP, PM, GC, OI) }\end{array}$ & 669.38 & 183 & 3.66 & 0.068 & 0.96 & 0.97 & 0.94 & 0.054 \\
\hline
\end{tabular}

Note: WP=workplace status; $\mathrm{PM}=$ prosocial motivation; $\mathrm{GC}=$ green creativity; $\mathrm{OI}=$ organization identification

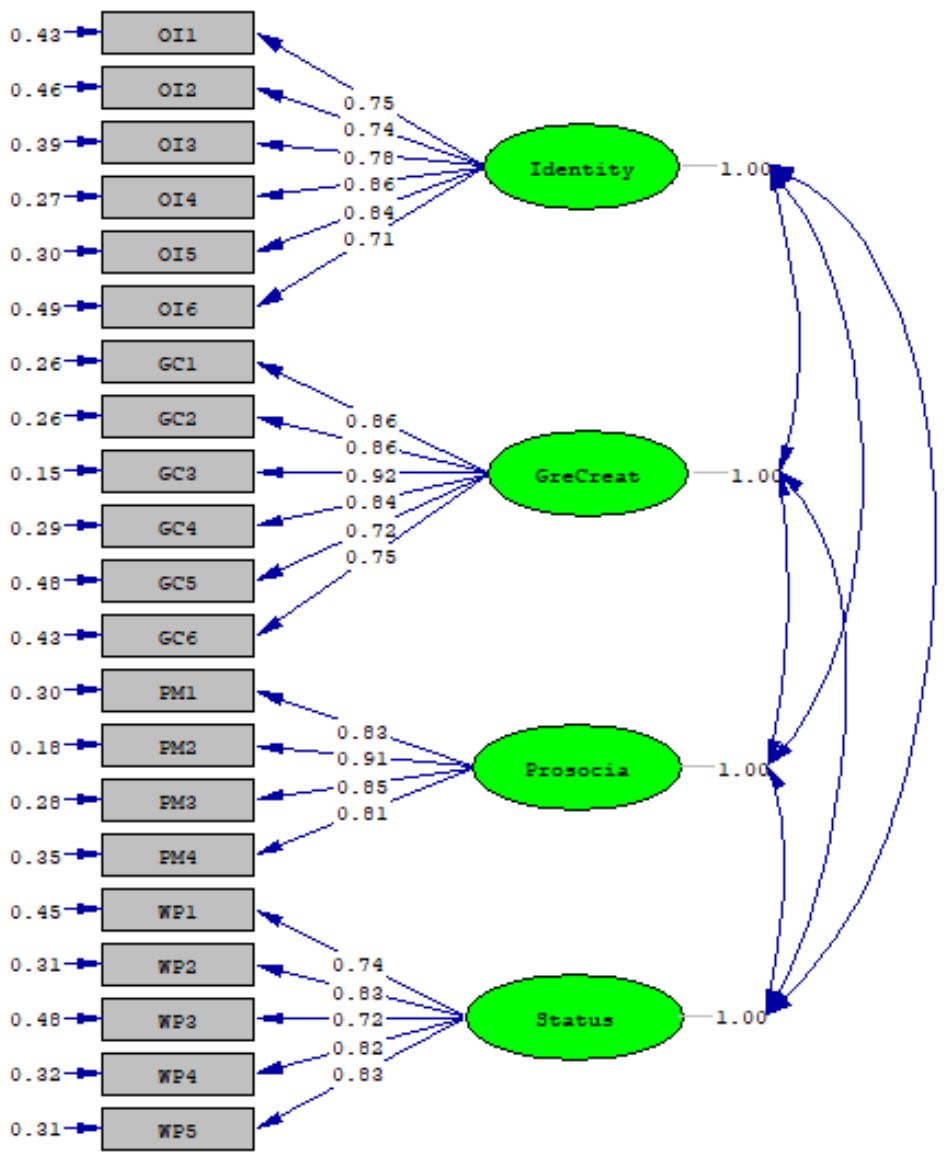

Figure 3. Validation factor analysis results of the model

\section{Hierarchical regression analysis}

First, we used a method of hierarchical regression analysis to test the mediating effect (Hayes, 2013). After controlling the four variables including age, working years, educational level and technical grade, workplace status still has a significant effect on green creativity, shown in Table 6 . And we found prosocial motivation partly mediated the relationship between workplace status and green creativity. The regression 
coefficients with organizational identification were significant that confirmed the moderation effect.

Table 6. Hierarchical regression analysis

\begin{tabular}{c|c|c|c|c|c}
\hline \multirow{2}{*}{ Variable } & \multicolumn{2}{|c|}{ Prosocial motivation } & \multicolumn{3}{c}{ Green creativity } \\
\cline { 2 - 6 } & $\boldsymbol{M 1}$ & $\boldsymbol{M 2}$ & $\boldsymbol{M 3}$ & $\boldsymbol{M 4}$ & $\boldsymbol{M 5}$ \\
\hline Age & 0.023 & 0.002 & -0.064 & -0.074 & -0.087 \\
Years of working & -0.001 & -0.011 & 0.006 & 0.006 & -0.006 \\
Degree of education & 0.126 & 0.127 & 0.040 & -0.017 & 0.040 \\
Technical grade & -0.032 & 0.005 & -0.138 & -0.123 & -0.097 \\
Workplace status & $0.613 * * *$ & $0.379 * * *$ & $0.495 * * *$ & $0.216^{* * *}$ & $0.252^{* * *}$ \\
Prosocial Motivation & & & & $0.454 * * *$ & \\
organization identification & & $0.383 * * *$ & & & $0.398^{* *}$ \\
interaction term & & 0.031 & & & $0.041^{* * *}$ \\
$R^{2}$ & 0.387 & 0.478 & 0.290 & 0.440 & 0.406 \\
Adjust $R^{2}$ & 0.378 & 0.467 & 0.280 & 0.430 & 0.394 \\
$\Delta R^{2}$ & 0.371 & 0.001 & 0.285 & 0.149 & 0.002 \\
$\Delta F$ & $203.182^{* * *}$ & 0.763 & $134.966 * * *$ & $89.262 * * *$ & 1.361 \\
\hline
\end{tabular}

$* * * p<0.001, * * p<0.01, * p<0.05$

\section{Moderated mediation effect test}

In addition, we performed a Bootstrap to get the confidence intervals of the moderated mediation model. With the increase of organizational identification, the correlation coefficient between workplace status and green creativity increased gradually, and the $95 \%$ confidence interval does not contain zero, see in Table 7 . This suggests that organizational identification can moderate the indirect effect between workplace status and green creativity, and the hypothesis $H_{3}$ is confirmed. Organizational identification is the boundary condition for workplace status to have an effect on green creativity.

Table 7. Result of the moderated mediation effect

\begin{tabular}{c|c|c|c|c}
\hline \multirow{2}{*}{ Organization Identification } & \multirow{2}{*}{$\boldsymbol{\beta}$} & \multirow{2}{*}{ Boot SE} & \multicolumn{2}{|c}{ Confidence interval } \\
\cline { 4 - 5 } & & & Lower 95\%CI & Lower 95\% CI \\
\hline 1-SD & 0.135 & 0.038 & 0.067 & 0.216 \\
1 & 0.148 & 0.028 & 0.099 & 0.207 \\
1+SD & 0.160 & 0.028 & 0.112 & 0.222 \\
\hline
\end{tabular}

\section{Conclusion}

In this paper, we proposed a moderated mediation model to explore the relationship between workplace status and green creativity. First, we found workplace status has a significant positive effect on green creativity, and this is very important for the management practices. Second, we confirmed the mediation effect of prosocial motivation, which is an effective complement to the theoretical study of green creativity. In the end, we found organization identification can moderate the indirect effect, and this has a pioneering role in the research of workplace status and green creativity. 
Acknowledgements. This work was supported by the key project of China's National Social Science Foundation (18AGL012).

\section{REFERENCES}

[1] Aebischer, P. (2003): Creative disability/disabled creativity in henry green's 'blindness'. Studies in the Novel 35: 510-525.

[2] Albort-Morant, G., Leal-Millan, A., Cepeda-Carrion, G. (2016): The antecedents of green innovation performance: A model of learning and capabilities. - Journal of Business Research 69: 4912-4917.

[3] Amabile, T. M. (1997): Motivating creativity in organizations: On doing what you love and loving what you do. - California Management Review 40: 39-58.

[4] Amabile, T. M., Conti, R., Coon, H., Lazenby, J., Herron, M. (1996): Assessing the work environment for creativity. - Academy of Management Journal 39: 1154-1184.

[5] Anderson, C., Hildreth, J. A., Howland, L. (2015): Is the desire for status a fundamental human motive? A review of the empirical literature. - Psychological Bulletin 141: 574601.

[6] Ashforth, B. E., Harrison, S. H., Corley, K. G. (2008): Identification in organizations: An examination of four fundamental questions. - Journal of Management 34: 325-374.

[7] Baron, R. M., Kenny, D. A. (1986): The moderator-mediator variable distinction in social psychological research: Conceptual, strategic, and statistical considerations. Journal of Personality and Social Psychology 51: 1173-1182.

[8] Bollen, K. A., Stine, R. (1990): Direct and indirect effects: Classical and bootstrap estimates of variability. - Sociological Methodology 20: 115-140.

[9] Chen, Y.-S., Chang, C.-H. (2013): The determinants of green product development performance: Green dynamic capabilities, green transformational leadership, and green creativity. - Journal of Business Ethics 116: 107-119.

[10] Dawson, J. F. (2014): Moderation in management research: What, why, when, and how. Journal of Business and Psychology 29: 1-19.

[11] Djurdjevic, E., Stoverink, A. C., Klotz, A. C., Koopman, J., Da, M. V. S., Yam, K. C., Chiang, J. T. (2017): Workplace status: The development and validation of a scale. Journal of Applied Psychology 102: 1124-1147.

[12] Du J., Li Q., Qiao F., Yu L. (2018): Estimation of vehicle emission on mainline freeway under isolated and integrated ramp metering strategies. - Environmental Engineering and Management Journal 17(5): 1237-1248.

[13] Eisenhandler, S. A. (2009): The greening of creativity and spirituality in 'dooryard' gardeners. - Gerontologist 49: 136-136.

[14] Farooq, O., Rupp, D., Farooq, M. (2017): The multiple pathways through which internal and external corporate social responsibility influence organizational identification and multifoci outcomes: The moderating role of cultural and social orientations. - Academy of Management Journal 60: 954-985.

[15] Gong, D., Liu, S., Tang, M., Ren, L., Liu, J. (2018): Revenue sharing or profit sharing? An internet production perspective. - Advances in Production Engineering \& Management 13(1): 81-92.

[16] Grant, A. M. (2007): Relational job design and the motivation to make a prosocial difference. - Academy of Management Review 32: 393-417.

[17] Hayes, A. F. (2013): Introduction to mediation, moderation, and conditional process analysis: A regression-based approach. - Journal of Educational Measurement 51: 335337.

[18] Hennessey, B. A., Amabile, T. M. (1998): Reward, intrinsic motivation, and creativity. American Psychologist 53: 674-675. 
[19] Huppmann, D., Gidden, M., Fricko, O., Kolp, P., Orthofer, C., Pimmer, M., Kushin, N., Vinca, A., Mastrucci, A., Riahi, K., Krey, V. (2019): The message(ix) integrated assessment model and the ix modeling platform (ixmp): An open framework for integrated and cross-cutting analysis of energy, climate, the environment, and sustainable development. - Environmental Modelling \& Software 112: 143-156.

[20] Jia, J. F., Liu, H. X., Chin, T. C., Hu, D. Q. (2018): The continuous mediating effects of ghrm on employees' green passion via transformational leadership and green creativity. Sustainability 10.

[21] Lichtenfeld, S., Maier, M. A., Buechner, V. L., Elliot, A. J. (2018): Ambient green and creativity. - Creativity Research Journal 30: 305-309.

[22] Mackinnon, D. P., Lockwood, C. M., Hoffman, J. M., West, S. G., Sheets, V. (2002): A comparison of methods to test mediation and other intervening variable effects. Psychological Methods 7: 83-104.

[23] Mael, F., Ashforth, B. E. (1992): Alumni and their alma mater: A partial test of the reformulated model of organizational identification. - Journal of Organizational Behavior 13: 103-123.

[24] Magee, J. C., Galinsky, A. D. (2008): Social hierarchy: The self-reinforcing nature of power and status. - Academy of Management Annals 2: 351-398.

[25] Moratis, L., Melissen, F. (2019): How do the sustainable development goals question rather than inform corporate sustainability? - Resources Conservation And Recycling 141: 253-254.

[26] Pombo, O., Rivela, B., Neila, J. (2019): Life cycle thinking toward sustainable development policy-making: The case of energy retrofits. - Journal Of Cleaner Production 206: 267-281.

[27] Sawyer, R. K. (2017): Creativity research and cultural context: Past, present, and future.Journal of Creative Behavior 51: 352-354.

[28] Shrout, P. E., Niall, B. (2002): Mediation in experimental and nonexperimental studies: New procedures and recommendations. - Psychological Methods 7: 422.

[29] Song, W. H., Yu, H. Y. (2018): Green innovation strategy and green innovation: The roles of green creativity and green organizational identity. - Corporate Social Responsibility And Environmental Management 25: 135-150.

[30] Spanjol, J., Tam, L., Tam, V. (2015): Employer-employee congruence in environmental values: An exploration of effects on job satisfaction and creativity. - Journal of Business Ethics 130: 117-130.

[31] Wang, L., Preacher, K. J. (2015): Moderated mediation analysis using bayesian methods. - Structural Equation Modeling A Multidisciplinary Journal 22: 249-263.

[32] Wang, X., Zhou, K., Liu, W. (2018): Value congruence: A study of green transformational leadership and employee green behavior. - Frontiers in Psychology 9.

[33] Wrzesniewski, A., Dutton, J. E., Debebe, G. (2003): Interpersonal sensemaking and the meaning of work. - Research in Organizational Behavior 25: 93-135.

[34] Zhou, S., Zhang, D., Lyu, C., Zhang, H. (2018): Does seeing "mind acts upon mind" affect green psychological climate and green product development performance? The role of matching between green transformational leadership and individual green values. Sustainability 10.

[35] Zhu, Y.-Q., Gardner, D. G., Chen, H.-G. (2018): Relationships between work team climate, individual motivation, and creativity. - Journal of Management 44: 2094-2115.

[36] Zinko, R., Ferris, G. R., Humphrey, S. E., Meyer, C. J., Aime, F. (2012): Personal reputation in organizations: Two-study constructive replication and extension of antecedents and consequences. - Journal of Occupational and Organizational Psychology 85: 156-180. 